\title{
Recognition of Application-oriented University Practice Teaching
}

\author{
Junxia Chen \\ Hotel Operation and Management Department, Guilin Tourism University, Guilin, 541006, China
}

Keywords: Application-oriented university interns, Practice subject, Practice, Teaching.

\begin{abstract}
The practice link is often deemed as the special link of application-oriented university teaching. In this paper, practice is regarded as a course to build it. This paper focuses on the course objective of application-oriented university practice teaching, learning features and learning type of application-oriented university interns, features of practice teaching guidance and recognition of the enterprises participating in practice teaching.
\end{abstract}

\section{Introduction}

Practice teaching is an important link in the teaching link of application-oriented university. It not just occupies long course hours and course period. From the perspective of course effect, it not just involves students' ability to apply course knowledge in practical work, but also concerns their cultivation of vocational ability and character. So, the cognition of application-oriented university practice teaching cannot only rest on the required teaching link. Universities should really regard it as a course to better build it. Course objective must be known clearly in course building. Meanwhile, students' learning features and learning type, teaching guidance method and resource building, teaching evaluation requirement and the role of enterprises participating in the practice should be well recognized.

\section{Course objective of application-oriented university practice}

Firstly, enhance and consolidate knowledge. Just as Broome said, "knowledge demand and application in work activity can achieve knowledge consolidation." The rationality of work steps and process can be rethought in work practice.

Secondly, enhance learning motivation and confidence. Through practice, on the one hand, application-oriented university interns can see the significance of academic knowledge for the real world; on the other hand, they may generate a profound connection between themselves and the real world, and know and position themselves again in the relation between themselves and the future.

\section{Cognition of learning features and type of application-oriented university interns}

\section{Learning features of application-oriented university interns}

Firstly, learning time fragmentization. In traditional teaching, teaching time presents the feature of concentration and unity. Teaching focuses on teacher, classroom and textbook. The study of application-oriented university interns presents the feature of fragmentization. They learn within working time and arrange learning time according to position features and requirements. Besides, they learn in their spare time. Thus, linear feature of traditional learning is broken from time dimension.

Secondly, learning space diversity. In traditional teaching, teaching space is mainly based on the classroom. The space shows closeness and oneness. The learning space of application-oriented university interns is real and complex occupational environment. Due to different working tasks and working objects, occupational environment of application-oriented university interns extends. 
Thirdly, explicit discreteness of learning content. In traditional teaching, teaching content is mainly based on subject knowledge or course knowledge. The knowledge presents the features of logic and systematicness. All learning contents of application-oriented university interns in the practice process show the feature of explicit discreteness due to fragmentization and difference of individual learning time as well as learning space richness and extension.

Fourthly, learning process staging. In traditional teaching, teaching process is the knowledge accumulation process as learning stage dividing mark. The psychological, emotional and attitude changes of learning subjects are often ignored. In the practice process, learning of application-oriented university interns will present four obvious stages: adaptive phase, mature period, numb period and struggling stage.

\section{Type of application-oriented university interns}

\section{Independent study}

Independent study is a process and also a learning ability. In the whole learning process, application-oriented university interns need goal setting, self-adjustment, self-observation, self-judgment and self-reflection. Ability acquisition manifests from control by others to self-control and from passive dependence to conscientious initiative. To be specific, in the practice process, they need to constantly adapt and challenge according to the analysis of miscellaneous job tasks and their own ability, and set their learning goals. Meanwhile, they need to make corresponding learning plan according to goals, consciously monitor learning progress, regulate emotion and rationally evaluate learning outcome. Since they continuously try independent study in the practice process, their sense of self-efficacy is accumulated and motivated. They gain joys and learn continuously due to the feeling of self-value achievement.

\section{Situation-based learning}

The working process of application-oriented university interns is also a learning process. Understanding the generation of situation problems such as working environment and job tasks and solving them is the way for interns to enter the situation-based learning. In the occupational situation, they achieve learning in the occupational situation through changing and cognitive cultural. Firstly, accept the hint of occupational situation, and understand the culture in infected occupational situation. As learners gradually enrich their cognition of the situation, their perception will reshape occupational culture. Secondly, adapt to and cope with real and complex situation problems; participate, negotiate and reach an agreement in the occupational situation. Thirdly, learn to create community culture in the occupational situation; break through previous relationship between employer and employee and present a new learning relation - modern apprenticeship system. Learners will usually experience the process from being at a loss and suspending the problem to imitating others and themselves.

\section{Cognition of practice teaching guidance features in application-oriented university}

\section{Practice teaching guidance method of application-oriented university}

Firstly, inquiry method. Inquiry guidance permeates strong consciousness of problems. It concerns about the fusion of study and work, and pays attention to problem introspection and criticism. Usually, the interns are guided to pay attention to, imitate and learn the tacit knowledge of masters or partners in the community. The conversation and contact attitude always runs through the guiding process. The significance of every tiny problem for "the student" is respected. Each student has different experience, perceptivity and comprehension. Such "peculiarity" exactly reveals the input degree and working quality. For these problems, the guidance should not just rest on the fact level, but also should be based on value and significance.

Secondly, comprehension method. Comprehension guidance encourages learning subjects to be immersed in the practice activity, enjoy the joys and gain "immersion experience" or "peak experience". Such experience is based on students' active participation in work and application of knowledge to experience the power of life and achieve their life value. In the guiding process, the 
practice subjects should be encouraged to gradually improve their knowledge structure and keep enriching their emotional experience. It is required to not just comprehend the knowledge itself, but also walk out of closed and narrow attitude to life and achieve surpassing.

Thirdly, sectioning method. Segmenting guidance aims at four different periods of practice subjects in the practice process. Adaptive phase: guide students to adjust their mentality and adapt to the position as soon as possible; mature period: encourage students to work independently and accept more complex job tasks; numb period: encourage work shift and rethink work problems; struggling period: guide to make the view of problem thinking broader and see future occupational development direction.

\section{Teaching resource construction about application-oriented university practice}

Effective teaching material preparation can let practice course pay more attention to systematization and professionalization. According to professional requirements and features of four practice stages, teaching materials can be divided into three stages: pre-practice, in-practice and post-practice. Pre-practice corresponds to adaptive phase. In-practice corresponds to mature period and numb period. Post-practice corresponds to struggling stage. Teaching materials stress practice subjects' practice and cultivation of introspection ability. Especially in in-practice, the teacher prepares typical work tasks and requires the practice subjects to complete them and to narrate the events happening in work in the form of practice log. Moreover, relevant teaching resource construction also involves practice website construction and development of virtual interactive learning game. Practice website is open and interconnected, which is favored by young people. Causes should be provided at regular time according to different departments, working process and tasks to trigger practice subjects to think, dialogue or follow up freely. The development of virtual interactive learning game also adopts multimedia internet technology to create a game world close to reality. The practice subjects enter the virtual world and solve problems according to the steps. Interestingness of games will simulate learning interest of practice subjects.

\section{Evaluation of application-oriented university interns}

The evaluation of application-oriented university interns should reach the all-round, objective and incentive effect. Firstly, evaluators own the feature of diversity, including teachers in the university, masters and leaders of the enterprise as well as practice subjects. Secondly, the evaluation content contains skill, strategy, professional ethics and personal integrity. Thirdly, the evaluation method combines qualitative and quantitative evaluation. Finally, the guiding role of evaluation should be exerted. The evaluation aims to help interns to see their potential, know themselves, establish confidence and motivate their exploration of knowledge. The evaluation content and result should be made public to the interns to achieve the original intention of evaluation.

\section{Cognition of enterprises participating in practice teaching}

Enterprises set up the platform for training practice subjects and provide real working environment. So, enterprises are the important partners of talent training in application-oriented universities. A good enterprise is not just a flag of industrial development, but also trains students and teachers.

\section{Confusion of interns in working process}

Firstly, they cannot contact typical job tasks and core contents. "Legal peripheral participation" does not always work. In reality, many interns will be in the stage of peripheral participation all the time. Just like the interns working in the butchery observed by Lave and Wenger, they always work in the assembly line to sort and pack products. The huge cartons ward off their sight for the key work. Many interns wipe cups in the drink and beverage department in the whole internship. There are numerous such cases. Secondly, wrong examples and nonstandard processes are learned in practice. For some enterprises, interns must implement nonstandard skill operation and unreasonable process setting. Such negative reinforcement effect is magnified, which is adverse to the growth of interns. 
Thirdly, some rights and interests of interns are not safeguarded. Many problems exist such as unfair wage and treatment as well as unsound medical treatment of work-related injury.

\section{Selection of enterprises participating in practice teaching}

About the selection of enterprises participating in practice teaching, universities usually choose some bran enterprises with high popularity and good reputation. On the one hand, these enterprises provide many positions and meet the mass education demand of application-oriented universities. On the other hand, these enterprises manage interns in accordance with the requirements of human resource management. When there is short of practice guiding teachers, normative management of an enterprise is especially important. There are three purposes for enterprises to employ interns. Firstly, to gain profits. To reduce the labor cost, enterprises employ interns to replace permanent worker. Secondly, for the purpose of future development. To absorb more excellent workers, enterprises pay high attention to intern training. Thirdly, to serve the society and region. Enterprises play the role of social servant and regard social responsibility as their mission. From the purposes, we can find that both noble altruism and selfish egoism exist. How to arouse enterprises' social responsibility?

\section{To arouse enterprises' social responsibility}

Enterprises' social responsibility means enterprise not merely consider economic benefit, but also undertake social benefit. How to make enterprises take the initiative to undertake social responsibility and protect interns' interests. There are two major ways. Firstly, impose pressure and force enterprises to fulfill social responsibility. The interests of interns may be protected through appraisal of industry association and improvement of labor law. Secondly, dialogue and cooperation. The universities, industry association and local government should exchange to co-design and participate in intern program management.

\section{Acknowledgements}

This paper is a stated result of educational reform project in Guangxi Autonomous Region "Off-campus Practical Education Base for Hotel Management Specialty".

\section{References}

[1] Donald A Schoen, Cultivating Response Practitioners: A New Design about Pedagogy in Professional Field, Translated by Hao Caihong et al., Beijing: Science and Education Press, 2008.

[2] Silberstein, S., Techniques and Resources in Teaching Reading, 2002, Shanghai Foreign Language Education Press, P3-18, 101-111.

[3] Ur, P. A Course in Language Teaching: Practice and Theory, 2000, Foreign Language Teaching and Research Press, Module 10 .

[4] Harmer, J., The Practice of English Language Teaching new edition, 1991, Longman, Chapter 10 . 